\title{
GREEN AND RESILIENT HEALTH INFRASTRUCTURE
}

\author{
Yatin Choudhary and Hari Kumar
}

\section{Introduction}

A green building is a structure that is environmentally responsible in its design, construction and operation, consequently improving the quality of both its indoor and outdoor environments. In healthcare, green infrastructure deals mainly with reducing the carbon footprint and thereby mitigating the impact on climate change. When implemented effectively, it can also provide the aesthetic component and improve the well-being of people using healthcare facilities, both patients and professionals. Health facilities have an environmental impact on the natural resources they consume, starting with the construction materials and the generated waste. Green infrastructure improves environmental sustainability with the usage of environment-friendly resources and practices, and by releasing well-treated and less harmful waste to its surroundings.

Resilient healthcare infrastructure, on the other hand, is that which can withstand extreme weather events (such as heavy precipitation, heatwaves, coldwaves, flooding, etc.) and cope with the consequent health impacts. These extreme weather events disrupt either the infrastructure or the function of the healthcare facilities completely or in varying degrees, right when they are needed the most, causing adverse psychosocial outcomes, injuries and deaths. A resilient hospital building can resist the impact of natural hazards, thereby allowing health facilities to remain functional during a calamity and in its immediate aftermath.

The concept of green buildings is not unique to healthcare, but hospitals do face unique challenges in terms of sustainability and disaster resilience, chiefly because they are resource- and energy-intensive. Similar to the medical doctrine of do no harm, it is important to follow green building principles and do the least harm to the environment. It is often thought that green designs and disaster-resilient designs are mutually exclusive, and that one aspect has to be compromised in order to cater to the other, but this is 
untrue. In fact, considering the multi-hazard prone nature of our country, it is vital for environmental sustainability that healthcare infrastructure be both green and resilient. Sometimes, making a building disaster-resilient may increase the environmental impact, and it can become challenging to balance the needs for resilience and optimum design requirements for resource efficiency in green buildings. This chapter will explore the means to achieve convergence between these needs, providing readers with an understanding of the following:

1. How to design and develop health facilities that are both green and resilient to disasters.

2. How to make existing buildings adapt to changing environmental conditions because of extreme weather events that are mainly attributable to climate change.

\section{Green infrastructure}

Green buildings are, by definition, resource-efficient and therefore have smaller environmental footprints. They are designed to optimise the onsite available resources such as sunlight, ventilation, water and energy. They are built of environmentally friendly materials, use energy-efficient devices and appliances, use water conservation strategies such as rainwater harvesting, and generate energy from clean and renewable sources (solar, wind or biogas). An important aspect of green hospital buildings is that they provide better indoor environment conditions for their occupants.

Green buildings are designed according to the functional requirements defined in standards and codes. In 2016, sustainable building design was incorporated into the National Building Codes. For energy efficiency, Energy Conservation Building Codes were introduced in 2007 (and updated in 2017). Sustainability was included in the Model Building Byelaws, 2016. There are several frameworks available in India for the design of green buildings including the AHPI Standard for Green and Clean Hospitals. The prominent rating systems that assess and certify the buildings on the basis of nationally acceptable benchmarks include a) Green Rating for Integrated Habitat Assessment (GRIHA), developed by the GRIHA Council, b) Indian Green Building Council (IGBC) rating systems, c) Leadership in Energy and Environment Design (LEED) developed by the US Green Building Council, and d) Excellence in Design for Greater Efficiencies (EDGE) by International Finance Corporation (IFC). In all of these, common green building principles utilise considerations such as land use, siting, low water and energy usage, utilisation of locally available materials, adoption of better standards of ventilation, day lighting and environment-friendly materials. These considerations are demonstrated in the case study of a green healthcare facility in Kurla, Mumbai (Box 13.1). 


\section{Box 13.1 Case study}

\section{Kohinoor Hospital in Kurla, Mumbai - the first LEED platinum-rated hospital in Asia}

Kohinoor Hospital was built using an environmentally sensitive design that not only conserves water and electricity, but also positively impacts the hospital's clinical environment by improving air quality, utilising natural sunlight and reducing a wide range of pollutants. During construction, the hospital used more than $29 \%$ of recycled material and $72 \%$ of regional material manufactured within a radius of $800 \mathrm{~km}$; appropriate construction waste management practices were followed to ensure that waste was recycled where possible and not diverted to landfills; and scrap steel was sourced and used for the overhead tank foundation.

Water efficiency was achieved by using urinal sensors, fixtures with low flow rates, and efficient grey water management. The landscaping requires no irrigation and the hospital's sewage treatment plant of 130 KLD treats $100 \%$ of the waste water.

The windmill installed by the hospital generates power offsite equivalent to $90 \%$ of the hospital's total requirement, hugely reducing its carbon footprint. The hospital conducted a detailed study of the solar path of the sun before finalising the orientation of the building, and its façade was designed with double glazed units of high-performance reflective glass to ensure that solar heat does not enter the building, whilst simultaneously ensuring that it is well-lit during the day. Solar panels on the roof are used for heating $84 \%$ of the water used by the hospital. Low wattage CFLs and LEDs were used in the lighting design and light fixtures, adding to the energy savings.

With respect to indoor air quality, the building has a no smoking policy; and the use of MERV-13 filters and $\mathrm{CO}_{2}$ sensors has increased the delivery of fresh air by 30\%. Mr. Unmesh Joshi, CMD of the Kohinoor Group, says, "Being green has a profound effect on the healing process, and what's good for the environment will be good for our patients.”

Source: https:/www.mgsarchitecture.in/building-materials-products/technologyautomation/273-kohinoor-hospital-1st-leed-platinum-rated-project-in-asia2nd-in-the-world.html

\section{Functionality of health facilities in emergencies}

As stated above, health facilities in our country should be resilient to every hazard that can affect their functionality. Staying safe during and after disastrous events poses a unique challenge for every medical care facility in 
terms of infrastructure, capacity and preparedness. However, for hospital buildings with a post-disaster role, it is not enough to only ensure the safety of the occupants of the building; the hospital building must be functional in all respects even during disasters, as it is expected to take in a surge of affected patients (Box 13.2). For a hospital to be functional during emergencies, the structure should remain largely undamaged and the facility should function as normal. For instance, a hospital emergency department where back-up electricity and water supply have been lost will not be able to serve a meaningful purpose in saving lives after the occurrence of a disaster.

\section{Box 13.2}

When hospitals are affected by disasters, there are health-related, social and economic repercussions. The health impact of hospitals being affected by disasters include the lapses in medical care being provided to victims of a disaster, lapses in preventive medicine and lapses in public health response. The social impact of hospitals being affected by disasters includes a loss of morale in the affected community which can affect the long-term recovery and sense of well-being of the community. The economic impact of hospitals being affected by disasters is enormous, given the huge investments required to be made to construct hospitals and the expensive equipment that is lost when disasters strike hospitals. Even the use of temporary field hospitals as a contingency measure is economically unviable. It is an attested fact that the costs involved to mitigate and prepare hospitals for disasters are far less than those required for re-building hospitals after they have been damaged by disasters. - National Disaster Management Guidelines, page 2.

A hospital needs to fulfil certain criteria for continued functionality in the aftermath of a natural disaster. We will examine the resilience and environmental challenges of each of these aspects after understanding the hazards the location is prone to.

\section{a) Safe and functional green buildings}

One of the earliest decisions to take in the lifespan of any health facility is the selection of the hospital site. A facility close to public facilities and even within communities reduces long-term costs and the environmental effects of transportation. Depending on the location, hospitals might be prone to different natural hazards such as earthquakes, landslides, cyclones, storm surges, or heavy rainfall. It should be borne in mind that during disastrous events and emergency situations, unlike in other buildings, evacuating 
patients from a healthcare facility will be extremely complex even with detailed evacuation plans. The site selection should take these aspects into consideration. Sandy soils with high water tables will amplify the effects of earthquakes and could undergo liquefaction, which can be dangerous for buildings. Other important factors that must be ensured during siting is to keep health facilities away from flood plains, landslide-/rock fall-prone areas, storm surges, tsunami inundation areas and so on. In the Indian context, the design of the building should consider all hazards that can affect the location using the Vulnerability Atlas of India (Building Materials and Technology Promotion Council, Ministry of Housing and Urban Affairs, Govt. of India, 2019).

Designers should take special care to follow all provisions as per the building code to ensure the safety of the roofs and external facades during earthquakes and high winds. In fact, the National Disaster Management Authority Guidelines on Hospital Safety (National Disaster Management Authority, Government of India, 2016) stipulate that hospital buildings with critical functions should be designed beyond the building codes, as these must remain functional in the events of crisis.

Gandhiji once said, "The ideal house in an ideal village would be built with materials found within a five-mile radius from the house." This holds true even for the construction of health infrastructure, and the selected materials should be locally available as possible without compromising on quality. The same principle applies for all procurement, which is another reason that the location of the health facility's location should be such that most or all procurement can take place from within a reasonable distance.

On top of this, the health facility should be green and resource-efficient with a minimal environmental footprint. Making sustainability an integral part of the building design will bring about a reduction in the hospital's energy requirement. Ensuring the right building façade will not only reduce the cooling and lighting requirements, but also aid in improved occupant comfort. In a tropical country like India, extensive glazing material should be avoided for buildings. The designs should optimise the use of onsite resources like sunlight, water and energy for functional requirements and aim to operate efficiently with minimal external dependence.

\section{b) Retrofitting of existing health facilities}

In the case of existing buildings, hospitals can initiate "retrofit" projects, to incorporate these changes. The energy savings from these projects, through reduced cooling or lighting requirements, can pay for the cost of the projects in most cases. However, it should also be clear that many structural retrofits will involve some level of disruption of normal functioning of the building and the hospital administration should work closely with the engineering team to work out a disruption plan for the retrofitting work.

The task of retrofitting existing hospital buildings into more resilient buildings and at the same time reducing its environmental impact is 
challenging, and requires detailed planning and coordination between the structural engineers and the green building specialists. Energy-efficiency upgrades can be carried out during a structural retrofit that utilises natural daylight better, provides improved ventilation, brings in higher efficiency in lighting/heating/cooling needs and utilises renewable energy and green roofs. These can help existing health facilities remain safe in disaster situations and reduce their environmental footprint. Such retrofits offer high returns in terms of reduced utility costs, lower dependency on external power and water sources, and better indoor environment conditions, leading to a healthier, safer and much more comfortable setting for the patients and staff.

\section{c) Safe and functional utility systems}

The functionality of a hospital depends largely on the availability of its utility services such as electricity, water supply and medical gas supply. It is important for health facilities to minimise their dependence on external suppliers and be self-sufficient to the maximum possible extent, as the external supplies are likely to be affected by hazards such as earthquakes, floods, or cyclones.

According to the Hospital Safety Index (WHO, 2015b), hospitals should have back-up electricity sources to power the facility for at least three days before the restoration of external sources. Solar passive architecture and planned ventilation can help in achieving this and effectively reduce the power requirements for heating and cooling purposes. Improving energy efficiency and reducing dependency on fossil fuel energy by using renewable energy such as solar rooftop panels as backup, could make a hospital selfreliant during these periods. The maintenance department of hospitals should develop a disaster power supply plan to estimate the departmentwise needs for electricity and identify alternate sources for supply in advance.

The HSI also recommends provision for in-hospital storage of enough water to run the hospital for the three-day emergency period. The reduced dependence on external sources of water must be achieved by the adoption of planned measures in the form of water conservation, recycling and treatment. The maintenance department of hospitals should develop a disaster water supply plan to estimate both quantity and quality of water required to continue operation of the critical functions and to meet emergency needs.

\section{d) Safe and functional medical equipment}

The safety and functionality of a medical facility can be affected not just by the loss of utility supply, but also due to the occurrence of flooding or earthquakes. To overcome this, it is important that critical equipment needed in emergency responses are as protected as possible from natural calamities (Rodgers et al., 2009). For example, in the 2015 Nepal earthquake, solar panels that had not been anchored properly in many hospitals either fell down or collided against each other and were damaged. In 
another instance during the 2015 Chennai floods, a hospital situated on the banks of the Adyar River lost several patients who were on ventilators, as the back-up electricity equipment was kept in the basement, which flooded.

\section{e) Safe and appropriate medical supplies}

Post-disaster emergency treatment requires medical supplies, and this largely depends on the nature of the disaster that occurred. Medical supplies required for earthquakes, floods and fires are different, and disaster medical supplies kits should be available within the stores for any emergency as per the Hospital Disaster Management Plan (HDMP). However, in order to reduce wastage and pharmaceutical pollution, hospital pharmacies should have a clear plan to utilise the medicines including emergency medicines much before expiry dates with strict stock controls, ensuring that these are sent out either as donations to other health facilities, or via manufacturer take-backs.

\section{f) Safe and prepared staff members}

The functionality of a health care institution in a post-emergency situation also depends on the level of preparedness of the staff members. A robust HDMP, staff training and preparedness drills/table-top exercises to test the plan will play a crucial role in ensuring that staff are prepared to take up their roles as detailed in the plan. In the field of disaster resilience and in aspects of green hospitals, leadership support for staff members will play a pivotal role in creating long-term organization cultural change towards safer, greener hospitals.

Healthcare leadership can also look at international guidelines such as the SMART Hospitals Toolkit (PAHO, 2017), the WHO HSI and the existing Framework for Climate-resilient Health Care Systems (WHO, 2015) on how to achieve resilience in preparation for disaster occurrences.

\section{Key takeaways}

- A green and resilient health sector plays a critical role in mitigating natural hazard risks and the effects of climate change through the adoption of eco-friendly strategies.

- It is imperative that the health facilities bring together resilience and minimal environmental impact in their design, construction and operations.

- India is a vast country where different regions of the country are prone to different hazards, and these should be assessed at the local level in the form of a situational analysis before embarking on the design of new healthcare facilities or before retrofitting an existing building.

- A hospital can decrease its carbon footprint and demonstrate continued functionality in the aftermath of a natural disaster with safe and 
functional green buildings, retrofitted existing buildings for efficient operations, safe and functional utility systems, safe and functional medical equipment, safe and appropriate medical supplies, and safe and prepared staff members.

- Codes, frameworks and standards for green buildings and resilient infrastructure have been provided for reference.

\section{References}

Building Materials and Technology Promotion Council, Ministry of Housing and Urban Affairs, Govt. of India. (2019). Vulnerability atlas of India (3rd ed.) BMTPC. https://bmtpc.org/DataFiles/CMS/file/VAI2019/Index.html

National Disaster Management Authority, Government of India. (2016). National disaster management guidelines: Hospital safety. A publication of the National Disaster Management Authority, Government of India. ISBN: 978-93-84792-03-9

Pan American Health Organization. (2017). Smart hospitals toolkit. https://www.

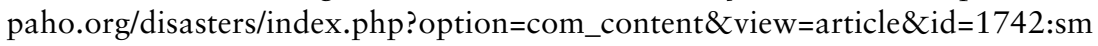
art-hospitals-toolkit\&Itemid=1248\&lang=en

Rodgers, J., Cedillos, V., Kumar, H., Tobin, L. T., \& Yawitz, K. (2009). Reducing earthquake risk in hospitals from equipment, contents, architectural elements and building utility systems. Geohazards International and Geohazards Society.

World Health Organization. (2015a). Operational framework for building climate resilient health systems. https://www.who.int/globalchange/publications/buildingclimate-resilient-health-systems/en/

World Health Organization \& Pan American Health Organization. (2015b). Hospital safety index: Guide for evaluators ( 2 nd ed.) World Health Organization. https://apps.who.int/iris/handle/10665/258966 